after 6 months ( $5 \%$ of cases) the average survival time was 15 months. Treatment had some effect in prolonging the course of the disease.

On radiological examination $93 \%$ of cases showed cardiomegaly.

On electrocardiographic examination $40 \%$ of cases showed right atrial enlargement, $42 \%$ left atrial enlargement, $83 \%$ right ventricular enlargement, and $54 \%$ left ventricular enlargement.

Certain electrocardiographic changes-namely, enlargement of the $\mathbf{P}$ waves, RS-T depression, and $\mathrm{T}$-wave inversion-are of some value in diagnosis.

We wish to acknowledge the leading part which Dr. Agnes Macgregor played in directing the Regional Paediatric Pathology Service in the South-Eastern Region of Scotland throughout a large portion of the period covered by this survey and her important contribution to this work. We also wish to thank Dr. Michael Matthews and Professor R. W. B. Ellis for advice and criticism. Dr. A. D. Bain is grateful for a grant from the Distillers Company Limited.

\section{REFERENCES}

Abildskov, J. A. (1959). Amer. Heart 7., 57, 930

Adams, F. H., and Katz, B. (1952). 7. Pediat., 41, 141.

Andersen, D. H., and Kelly, J. (1956). Pediatrics, 18, 513.

Apley, J.' (1961). Arch. Dis. Childh., 36, 366.

Blumberg, R. W., and Lyon, R. A. (1952). Amer. F. Dis. Child., 84, 291.

Dennis, J. L., Hansen, A. E., and Corpening, T. N. (1953). Pediatrics, 12, 130 .

Dimond, E. G., Allen, F., and Moriarity, L. R. (1955). Amer. Heart F., 50, 651 .

Edwards, J. E. (1959). In S. E. Gould's Pathology of the Heart, 2nd ed. Thomas, Springfield, Illinois

Halliday, W. R. (1954). Dis. Chest, 26, 27.

Hill, W. T., and Reilly, W. A. (1951). Amer. F. Dis. Child., 82, 579.

Johnson, F. R. (1952). Arch. Path., 54, 237.

Keith, J. D., Rowe, R. D., and Vlad, P. (1958). Heart Disease in Infancy and Childhood. Macmillan, New York.

Lambert, E. C., Shumway, C. N., and Terplan, K. (1953). Pediatrics,

11, 255. Interpretation, 4th ed. Macmillan, New York.

Rosahn, P. D. (1955). Bull. N.Y. Acad. Med., 31, 453.

Vlad, P., Rowe, R. D., and Keith, J. D. (1955). Brit. Heart F., 17, 189.

Willis, R. A. (1958). The Borderland of Embryology and Pathology. Butterworth, London.

Ziegler, R. F. (1951). Electrocardiographic Studies in Normal Infants and Children. Thomas, Springfield, Illinois.

\title{
Vagotomy in the Treatment of Perforated Duodenal Ulcer
}

\author{
JAMES I. H. HADFIELD, ${ }^{*}$ F.R.C.S. ; DAVID F. L. WATKIN, $\dagger$ F.R.C.S.
}

Brit. med. F., 1964, 2, 12-17

The basic treatment for perforated duodenal ulcer has long been suture or its variant, the application of a live omental graft (Roscoe Graham, 1937). Conservative treatment for perforation (Taylor, 1957) has enjoyed only limited support despite good results in some hands; a major disadvantage is uncertainty regarding the detailed diagnosis in terms of the site of the ulcer and possible obstructive effects. Such limited treatment is lifesaving in the majority of cases, although the results are less good in those patients with bleeding or pyloric stenosis; the case for adopting any more extensive operative procedure rests upon the $50 \%$ incidence of further disability in the ensuing years.

Emergency partial gastrectomy for perforation has generally been reserved in Britain for gastric ulcer and for those duodenal ulcers presenting with concomitant bleeding or pyloric stenosis as strong indications for definitive surgery. Despite several series with low mortality rates, partial gastrectomy has not found a larger place in the treatment of perforation, partly because it involves a rather extensive dissection in the presence of peritoneal contamination, and partly on account of its proportion of unfortunate sequelae both early and late (Muir, 1949 ; Wells, 1954 ; Stammers, 1955).

The introduction of vagotomy and a gastric-drainage procedure as elective treatment for duodenal ulceration (Beattie, 1950 ; Dragstedt, 1959 ; Burge and Clarke, 1959) offers a less drastic alternative in the treatment of perforated duodenal ulcer, and may justify some broadening of the indications for a definitive operation. In America Pierandozzi et al. (1957, 1960) and Harbrecht and Hamilton (1960) have reported their very satisfactory short-term results for selected series of duodenal perforations treated by vagotomy and pyloroplasty. We present the results of treatment of 61 perforated duodenal ulcers by vagotomy and a drainage procedure, together with follow-up

- Senior Surgical Registrar, Leicester Royal Infirmary.

t Surgical Registrar, Leicester Royal Infirmary. studies at periods of 18 months to 4 years. The late results of a local series of duodenal perforations treated by simple suture are given for comparison.

\section{The Patients}

The treatment of 177 patients with perforated duodenal ulcers presenting at the Leicester Royal Infirmary in 1959-63 is summarized in Table I. Sixty-one of these (52 males and 9 females) were treated by vagotomy and a drainage procedure. During this period 107 other patients with perforated duodenal ulcers were treated by simple suture. Conservative treatment for perforation was not employed, but four moribund or misdiagnosed patients were found at necropsy to have perforated duodenal ulcers. "Poor general condition" was regarded as a reason for, rather than against, surgery, so such bad-risk subjects are among those treated by simple suture.

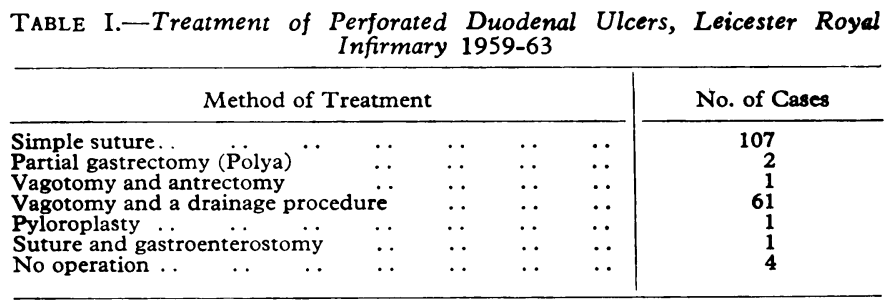

The patients were selected for vagotomy and a drainage procedure on account of a convincing history of peptic ulcer of two years or more (42 patients) or a previous perforation without other symptoms of ulcer (two patients), or, failing such a history, on the operative finding of an obviously chronic ulcer (16 patients). For one patient no such indication for a definitive operation was apparent, his history being only six months. Of the 42 patients with a "chronic" history, some 
presented as additional indications for definitive surgery, a history of previous perforation (6), past haemorrhage (7), concomitant bleeding (2), or the operative finding of pyloric stenosis (6). The 16 patients who lacked a two-year history admitted to no indigestion in 5 cases, had had indigestion for less than three months in 7 cases, and for more than three months in 4 cases. This group included one with concomitant bleeding and two with pyloric stenosis. The indications for vagotomy and drainage in this series of 61 patients are set out in Table II.

TABLE II.-Vagotomy Series : Indication for Definitive Operation

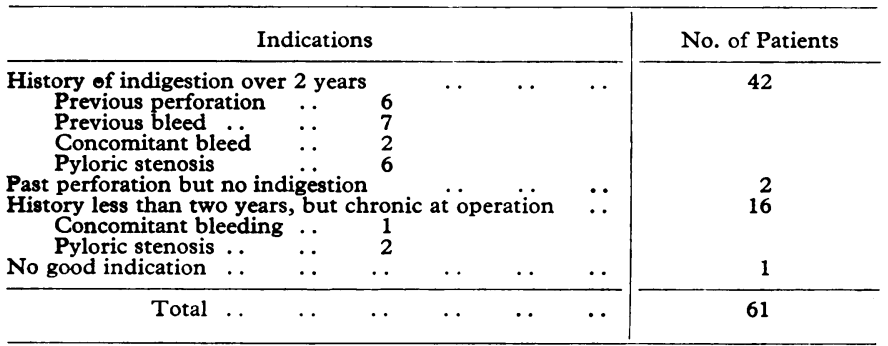

Patients were rejected for vagotomy and a drainage procedure if judged unfit for this more major operation. The requirements were not highly exclusive; the procedure was limited to simple suture only in those who were hypotensive and inadequately responsive to transfusion, or who were seriously disabled by other disease. Neither a long interval since perforation, nor extensive peritoneal soiling, of themselves led to rejection. The vagotomy-and-drainage group included 21 patients aged 60 or over (Fig. 1). By the time

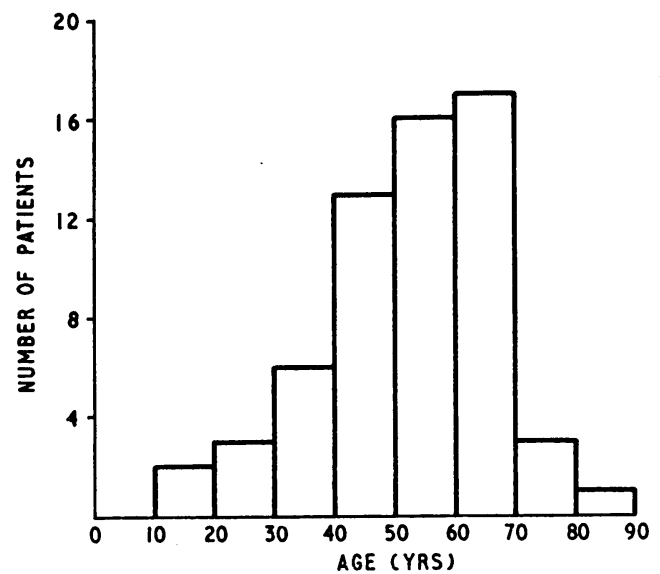

FIG. 1.-Vagotomy series (61 patients). Age distribution at time of perforation.

of operation 37 had been perforated for less than 6 hours, 18 for from 6 to 12 hours, and four for 12 to 24 hours. One had waited 55 hours and another had probably perforated 10 days previously; at operation in both these cases the leakage was found to be well localized (Fig. 2). Six patients had evidence of chronic bronchitis, and there was one case each of pulmonary tuberculosis, mitral stenosis (treated by valvotomy one year previously), and hypostatic leg ulcers. One lady aged 69 had marked senile dementia, while the oldest subject, a lady of 81 , was extremely cachectic. We present the group as a whole for consideration of the early postoperative results and have followed up the 39 survivors of the first 40 operations to assess their fate.

An indirect factor influencing the type of operation performed for an individual patient was the chance of which surgical registrar was on duty. Enthusiasts for vagotomy and drainage for perforated duodenal ulcers did this procedure whenever indicated, while others almost invariably employed simple suture. The group of 76 patients who survived this latter operation during 1959-61 have been reviewed as a check on the indications employed in selecting patients for definitive procedures. They comprise 67 males and 9 females, and their age distribution is broadly similar to that of the vagotomy

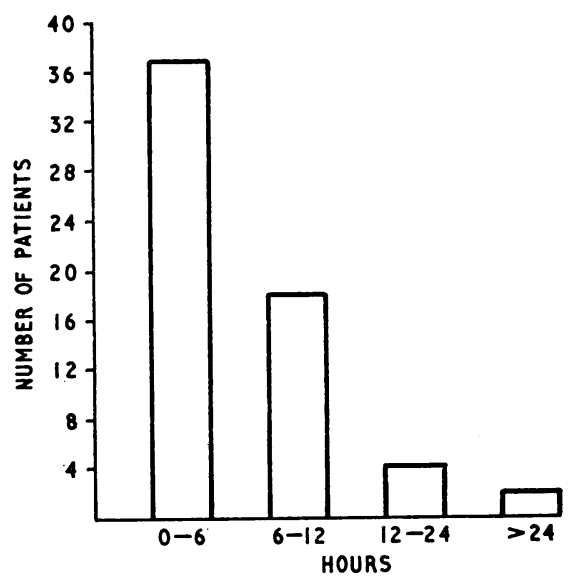

FIG. 2.-Vagotomy series. Delay between perforation and operation.

series (Fig. 3). This group, including as it does all those patients who were least fit for operation, is unsuitable as a standard for comparison of the short-term results of the vagotomy series. They have been reviewed to provide up-todate information on the late results of simple suture of perforated duodenal ulcers in this community.

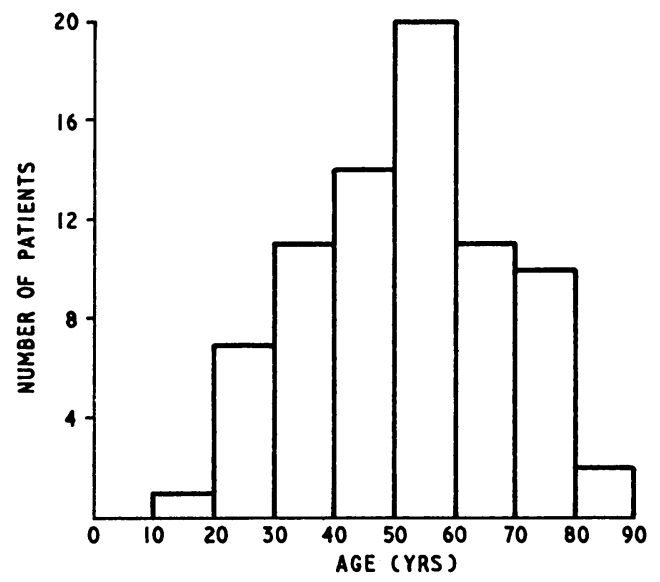

FIG. 3.-Simple suture series (76 patients). Age distribution at time of perforation.

\section{Vagotomy-and-drainage Group : Technique}

Diagnosis was based upon the typical symptoms and clinical signs of perforated peptic ulcer, and no unusual trend was noted. A straight $x$-ray film was taken in a proportion of cases-in particular when, clinically, a perforation seemed improbable. A nasogastric tube was passed as soon as possible and the stomach emptied. The necessary resuscitation by means of intravenous fluids (chiefly normal saline and plasma) was given rapidly, and the operation was undertaken under general anaesthesia as soon as practicable.

The abdomen was opened by a right upper paramedian incision, and the peritoneal cavity was mopped out. In all cases a bilateral, macroscopically complete vagotomy was carried out. The peritoneum at the hiatus was not closed, as it was thought preferable to allow free drainage into the peritoneal cavity should mediastinitis result from contamination by duodenal contents. In 11 of the earlier cases the perforation was closed and a retrocolic isoperistaltic, short-loop, juxtapyloric gastrojejunostomy with a non-valved horizontal stoma was made, 
anastomosis being by two layers of continuous catgut. In the remaining cases, 50 in all, pyloroplasty or, where convenient, anterior pylorectomy, excising the ulcer, was employed. In 49 cases the Mikulicz technique was followed; in the remaining case a tight stenosis below the ulcer made a Finney pyloroplasty appropriate (Table III). For most of the series the pyloroplasty was closed with two layers of continuous catgut, but latterly we have changed to a single layer of interrupted sutures. The tissues under maximum tension at the centre of the suture-line of a Mikulicz pyloroplasty are normal, in contrast to the oedematous margin encountered when suturing a perforation. The operations did not prove technically any more difficult than when done electively. In addition, one patient with gall-stones underwent cholecystectomy, and two spleens, ruptured during the operations, required removal. In one patient, a severe bronchitic, a temporary gastrostomy was made to avoid the use of a Ryle's tube.

\begin{tabular}{|c|c|c|}
\hline Vagotomy Combined with & & No. of Cases \\
\hline $\begin{array}{l}\text { Suture of perforation and gastrojejunostomy } \\
\text { Mikulicz pyloroplasty or anterior pylorectomy } \\
\text { Finney pyloroplasty .. }\end{array}$ & $\begin{array}{ll}\cdots & \cdots \\
\cdots & \cdots\end{array}$ & $\begin{array}{r}11 \\
49 \\
1\end{array}$ \\
\hline Total & . & 61 \\
\hline
\end{tabular}

Post-operatively, oral fluids were started at 12 to 48 hours according to the surgeon concerned. Gastric aspiration and intravenous fluids were required on the average for 48 to 72 hours. All received a course of systemic antibiotic, usually penicillin and streptomycin.

\section{Immediate Results of Vagotomy for Perforated Duodenal Ulcer}

There were three post-operative deaths in hospital, the details of these patients being as follows:

Case 1.-A 39-year-old man with a seven-year history of indigestion came to operation six hours after perforation. Subsequently he developed subphrenic and pelvic abscesses, which were drained, and later a faecal fistula formed at the site of abdominal drainage of the pelvic abscess, so a proximal colostomy was made. Then his abdominal incision broke down completely, requiring resuture. $\mathrm{He}$ gradually deteriorated and died on the 28th day. Post-mortem examination showed suppuration throughout the peritoneal cavity, apparently due to reperforation of the duodenum.

Case 2.-An extremely thin woman, aged 81, gave a 12-month history of indigestion. She was hypotensive on admission, but responded well to infusion of normal saline. At operation, 12 hours after perforation, the finding of tight pyloric stenosis demanded more than simple suture, so, despite her unfitness, vagotomy and pyloroplasty were carried out. Four days post-operatively a persistent paralytic ileus gave way to profuse diarrhoea of such magnitude that she died of electrolyte depletion with peripheral circulatory failure. Necropsy showed gross dilatation of the small intestine with an intact pyloroplasty and no intraperitoneal sepsis.

Case 3.-A 70-year-old man had a 24-year history of duodenal ulceration, including episodes of haematemesis 5 and 15 years previously. He was very thin and suffered from chronic bronchitis. Operation 10 hours after perforation disclosed pyloric stenosis, and vagotomy and pyloroplasty were performed. Three days after the operation paralytic ileus was followed by profuse diarrhoea, and he died, like the previous patient, of electrolyte and fluid loss and peripheral circulatory failure, with the further complication of bronchopneumonia. Post-mortem examination again showed small-bowel distension, an intact pyloroplasty suture-line, and the absence of intraperitoneal suppuration.

We do not know why the first of these patients leaked from his suture-line, so developing the extensive intraperitoneal sepsis to which he ultimately succcumbed.

The two frail and elderly patients who died both had pyloric stenosis as a strong indication for definitive surgery, and one in addition had had two past haemorrhages. There is no evidence on the cause of their severe ileus and terminal profuse diarrhoea. Clinically it was thought that they might be suffering from necrotizing enteritis, but this was not adequately demonstrated at necropsy. We are left, therefore, with a suspicion that vagotomy may have played an important part in producing ileus and diarrhoea. Perhaps more robust subjects would have survived these episodes, particularly if given greater quantities of intravenous fluid rather sooner. As a result of this experience we would now be inclined not to do a vagotomy for such elderly patients with perforation and pyloric stenosis, but to confine the procedure to pyloroplasty or simple suture with gastrojejunostomy.

The early post-operative morbidity (excluding the above three fatalities) is listed in Table IV. There were six chest infections, all resolving with antibiotics and physiotherapy. The patient with mitral stenosis developed pulmonary oedema, which satisfactorily responded to medical treatment. There was one case of paralytic ileus lasting six days and one subphrenic abscess. Three patients developed wound abscesses, and in one patient abdominal wound dehiscence occurred. A man aged 48 developed acute retention of urine and ultimately required prostatectomy. Twenty-three patients were discharged in a week or less and 26 more in the second week. Seven patients needed to be in hospital for 15-28 days-four on account of chest infections, two for wound sepsis, and one for wound dehiscence. The patient who required prostatectomy was discharged after 35 days and the one who developed a subphrenic abscess at three months.

TABLE IV.-Vagotomy Series : Post-operative Morbidity

\begin{tabular}{|c|c|c|c|c|c|c|}
\hline \multicolumn{6}{|c|}{ Complication } & $\frac{\text { No. of Cases }}{6}$ \\
\hline $\begin{array}{l}\text { Chest infection } \\
\text { Pulmonary oedema ... } \\
\text { Paralytic ileus (prolonged) } \\
\text { Subphrenic abscess ... } \\
\text { Wound infection } \quad \ldots \\
\text { Wound dehiscence } \\
\text { Acute retention of urine }\end{array}$ & $\begin{array}{l}\cdots \\
\cdots \\
\cdots \\
\cdots\end{array}$ & $\begin{array}{l}\cdots \\
\cdots \\
\cdots \\
\cdots \\
\cdots\end{array}$ & $\begin{array}{l}\cdots \\
\cdots \\
\cdots \\
\cdots \\
\cdots\end{array}$ & $\begin{array}{l}\cdots \\
\cdots \\
\cdots \\
\cdots \\
\cdots\end{array}$ & $\begin{array}{l}\cdots \\
\cdots \\
\cdots \\
\cdots \\
\cdots\end{array}$ & $\begin{array}{l}6 \\
1 \\
1 \\
1 \\
3 \\
1 \\
1\end{array}$ \\
\hline
\end{tabular}

Thus of 61 patients undergoing vagotomy and a drainage procedure for perforated duodenal ulcer, three died and nine developed complications sufficient to keep them in hospital for more than two weeks. Two patients were in hospital for more than a month-one on account of a subphrenic abscess and the other for prostatectomy.

\section{Late Results of the Vagotomy Group}

The 39 survivors of the first 40 vagotomy-and-drainage operations carried out for perforated duodenal ulcer at the Leicester Royal Infirmary were reviewed during the latter half of 1963 , giving a follow-up period of 18 months to 4 years. Only two ( $5 \%$ ) could not be traced, having left their lodgings. Information about one patient was obtained by letter from his general practitioner in Glasgow, and another had died. The remainder either attended a special follow-up clinic or were visited at their homes by one of us. The results of this review are summarized in Table V. We inquired fully into the presence of indigestion, dysphagia, or diarrhoea since the operation. Twenty-nine patients $(74.4 \%)$ remained free of indigestion; four of these had some diarrhoea, having two or three

TABLE V.-Vagotomy Series: Late Results at $1 \frac{1}{2}$ to 4 Years

\begin{tabular}{|c|c|c|c|c|c|c|}
\hline \multicolumn{5}{|c|}{ Results } & \multirow{2}{*}{ 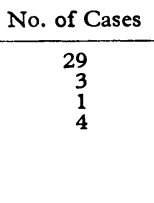 } & \multirow{2}{*}{$\begin{array}{c}\text { Percentage } \\
74.4 \% \\
7.7 \% \\
2.6 \% \\
10.3 \%\end{array}$} \\
\hline $\begin{array}{l}\text { No indigestio } \\
\text { Minor indige } \\
\text { Died with mi } \\
\text { Moderate to } \\
\text { Vagotom } \\
\text { Vagotom } \\
\text { No insul }\end{array}$ & $\begin{array}{l}\text { minor diarrhoea } \\
\text { n...j. } \\
\text { indigestion } \\
\text { ere indigestion } \\
\text { omplete ... } \\
\text { acomplete } \\
\text { est } \quad .\end{array}$ & $\begin{array}{l}\text { in } 4) \\
\cdots \\
\cdots \\
i \\
2 \\
1\end{array}$ & $\begin{array}{l}\ddot{*} \\
\ddot{*}\end{array}$ & $\begin{array}{l}\ldots \\
\cdots \\
\cdots\end{array}$ & & \\
\hline Untraceable & $\ldots$ & .. & & $\ldots$ & 2 & $5 \cdot 1 \%$ \\
\hline
\end{tabular}


bowel actions per day, either regularly or intermittently; but none regarded this as an important disability. Three patients $(7.7 \%)$ made minor complaints-one of flatulence, one of symptoms of oesophageal reflux, and one of epigastric pain during the first year after operation (but none in the subsequent two years). This last patient also has occasional diarrhoea. One elderly male, who died of unrelated disease nine months after the operation, had complained of vague indigestion when last seen as an out-patient.

Four patients $(10.3 \%$ ) complained of moderate or severe symptoms ; the details of these cases are as follows:

Case 4.-A man aged 29 at the time of perforation gave a fiveyear history of indigestion attributable to a duodenal ulcer proved by barium meal. During the four years since vagotomy and pyloroplasty he has suffered recurrent episodes of indigestion, losing on an average two months' time from work each year. Barium studies done six months post-operatively showed "a probable duodenal ulcer crater," but an insulin test meal (Hollander) indicated that vagotomy was complete. He is being managed conservatively, as he does not seem a good personality for any further surgery.

Case 5.-A man aged 58 gave a 20-year history of indigestion and was treated by vagotomy, closure of the perforation, and gastrojejunostomy. Six months post-operatively he complained of a return of symptoms. Barium-meal examination showed a gastrojejunal ulcer crater, but an insulin test meal showed only a slight rise in acid secretion; so it seemed that, at most, a small vagal twig had been missed. His symptoms ceased after a further six months, and he has remained well for the past two years.

Case 6.-A 35-year-old man presented with only one month's history of indigestion, but was found at operation to have a chronic duodenal ulcer and was therefore treated by vagotomy and pyloroplasty. Two months later his symptoms returned and an insulin test meal indicated that vagotomy was incomplete. Severe symptoms continued, so nine months from the time of perforation a transthoracic vagotomy was carried out. He has been symptom-free since then.

Case 7.-A woman aged 64 had only a one-week history of indigestion but proved at operation (vagotomy and pyloroplasty) to have chronic anterior and posterior duodenal ulcers. When seen 21 months later she complained of dysphagia and intermittent abdominal distension. The only clinical abnormality was a gastric splash, but barium studies showed a widely open pylorus and no delay in gastric emptying. There was slight deformity of the duodenal cap, but no ulcer crater was shown. As she was not complaining of pain, admission for an insulin test meal did not seem to be justified.

Of these four patients with major symptoms post-operatively, three were subjected to insulin test meals; one (Case 6) has an incomplete vagotomy, and another (Case 5) probably has some intact vagal fibres but has been well for the past two years. One patient (Case 4) continues to have considerable disability, and possibly has a recurrent duodenal ulcer, though he has been shown to have a complete vagotomy. The fourth patient (Case 7) has diverse complaints but seems unlikely to have a recurrent ulcer.

Thus, despite the possibly more difficult operative conditions following perforation, the procedure was carried out satisfac- torily, as there has been no evidence of subsequent gastric retention and only two (5.1\%) incomplete vagotomies have become apparent among a total of 39 operations. The expected vagotomy complication of diarrhoea has been at a $15.4 \%$ incidence, but in no case has it been regarded by the patient as a disability. There has been no evidence of the predicted complication of stenosing mediastinitis following perhiatal vagotomy in the presence of soiling from a perforated duodenal ulcer. In one patient who complained of dysphagia at follow-up, barium passed normally into the stomach. Overall the result was satisfactory in $84.6 \%$ and poor in $10.3 \%$.

\section{Late Results of Simple Suture}

The 76 patients who left hospital after simple suture of a perforated duodenal ulcer during the years 1959 to 1961 were reviewed. The choice of this group gave a follow-up period of two to five years. No useful information could be obtained about seven patients $(9.2 \%)$, except that two of them had died. Information about the other 69 patients $(90.8 \%$ ) was obtained by the same means as for the vagotomy group.

We found that three patients had died of their duodenal ulcers-two as a result of haemorrhage six months and nine months post-operatively. One died at home at four months, after several weeks of profuse vomiting. Definitive operations were carried out in 15 patients, including two presenting as emergencies with bleeding and one with a second perforation. These operations were all done within two years of the original perforation, and comprised 13 vagotomy-anddrainage operations and two Polya gastrectomies. Thirteen further patients were complaining of moderate or severe pepticulcer symptoms, requiring regular antacids and losing some time from work. Four patients who had died of other diseases were known to have suffered similar ulcer disability. Thus a total of 35 patients $(46.0 \%)$ had considerable further trouble after simple suture of a perforation. The remaining 34 traceable members of this group ( $44.7 \%$ of the total) were either alive with no significant symptoms (30 patients) or had died of unrelated diseases without ulcer symptoms (four patients).

These results have been listed on the left of Table VI, in which they have been correlated with various possible prognostic factors. The first four columns compare the fates of patients with histories of less than 2 years, 2-5 years, 6-9 years, and 10 or more years. It is seen that length of history is not a clear guide to the probability of future trouble, though the incidence is rather lower in the group with less than two years' history. Comparison of those whose ulcer was considered to be acute at operation (column 6) or chronic (column 7) shows that of the acute-ulcer patients one was alive with symptoms and four were symptom-free. Of the chronic-ulcer subgroup, seven had had further trouble, two dying of the ulcer and three more requiring definitive surgery, while none was symptom-free. The importance of chronicity at operation as a prognostic sign is

TABLE VI.-Simple-suture Series : Late Results at 2-5 Years

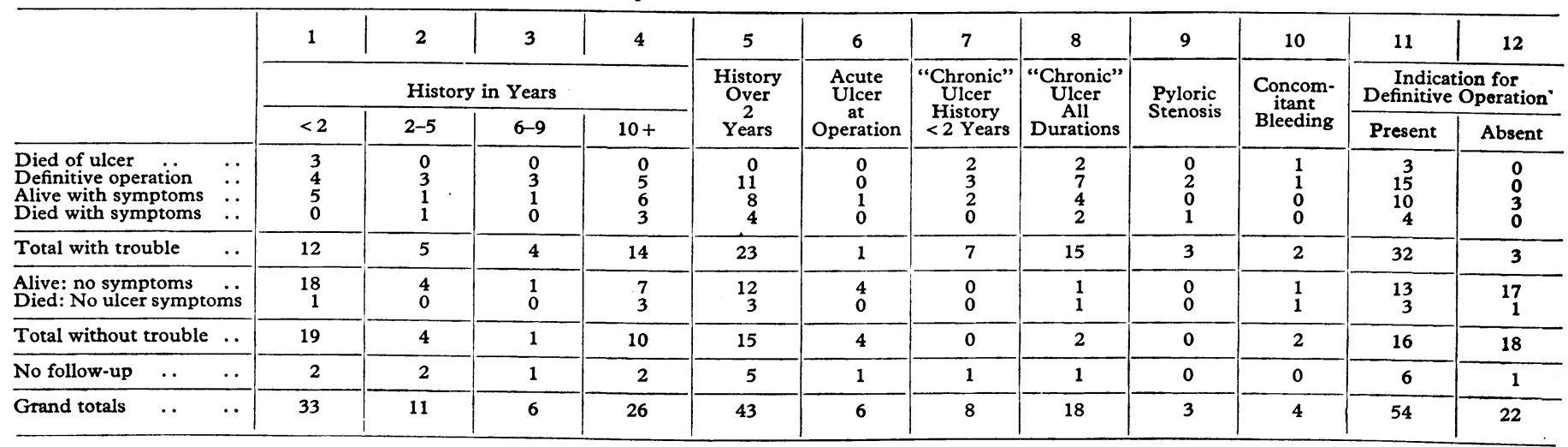


further borne out by grouping together all ulcers described as chrnnic (column 8) irrespective of length of history; of these 15 had further trouble and only two did not. All patients with a history of two years or more are amalgamated in column 5, to correspond to one of the major indications followed in the vagotomy series. Twenty-three of these had further trouble, including 11 who came to operation; 15 remained free of ulcer symptoms. Pyloric stenosis is seen in column 9 to carry its usual high risk of continuing disability, but, contrary to general experience, two of the four patients with concomitant bleeding have so far remained well (column 10).

Amalgamation of the contents of columns 5, 7, 9, and 10 produces a group who presented the indications for definitive surgery which we employed in the selection of the vagotomy series. The fate of these 54 patients is compared with the 22 who would still have been treated by simple suture (column 11 ; column 12). If these 54 patients had undergone vagotomy 32 would have been spared further trouble, but 16 would have had an unnecessarily major operation (six were untraceable). Of the 22 for whom simple suture would still have been employed under this regime, only three have had further symptoms, 17 are well, one has died, and one is untraceable.

\section{Discussion}

Perforated duodenal ulcers treated by the traditional operation of simple suture commonly give further trouble. Illingworth et al. (1946) found that of 733 cases of perforated peptic ulcer ( $87 \%$ of these being duodenal in site) treated by simple suture and followed up for one to five years, $40 \%$ had a return of symptoms within one year and $60 \%$ in two years. In each year of follow-up $2 \%$ reperforated, $2 \%$ underwent partial gastrectomy, and $1 \%$ bled. Gilmour (1953) followed up 160 perforated duodenal-ulcer patients treated by simple suture; of these $47 \%$ came to operation or had major symptoms, while $17 \%$ had mild symptoms. The present simple-suture series of 76 cases followed up at two to five years shows that $46 \%$ of the total (or $50.7 \%$ of those traceable) have had further trouble. Clearly, approximately $50 \%$ of all these patients would be better served by a definite operation initially, provided it could be safely and adequately accomplished in the presence of perforation. Judin (1937) and Nuboer (1951) published large series of perforated peptic ulcers treated by partial gastrectomy with low mortality rates of $3 \%$ and $3.8 \%$ respectively. Lowdon (1952) treated 51 of 65 consecutive perforated peptic ulcers by emergency partial gastrectomy, and all these patients survived. Histologically some of these ulcers were fairly acute, in contrast to Nuboer's finding that perforation occurred only in chronic ulcers. These acute ulcers were in patients with little history of indigestion. Lowdon doubted the wisdom of indiscriminate gastrectomy and suggested as indications gastric ulcer, previous perforation, concomitant haemorrhage, and evidence of chronicity. Avery Jones and Doll (1953) stated that an ulcer history of more than one year and a past proved ulcer double the risk of further trouble after perforation, and so recommended selective Polya gastrectomy for duodenal perforation in those patients with an ulcer proved by $x$-ray and a history exceeding one year and for those with concomitant bleeding. Lewis and Hamilton (1956), studying a group of 183 patients with perforated peptic ulcers, found that of those with symptoms for more than five years only $12 \%$ remained well after simple suture, and of 24 with a history of previous perforation or present bleeding or obstruction none was well. These papers provided a basis for the indications for definitive surgery employed in the present vagotomy series. The aim of selection is to ensure that as many patients as possible are saved from further serious ulcer disease while avoiding " unnecessary" major procedures. In addition to the cardinal indications of concomitant haemorrhage and pyloric stenosis, we accepted those with a history of duodenal ulceration extending over two years or more and those with little or no history, but a chronic ulcer at operation.

We found, in fact, that a chronic history or chronic operative findings encompassed all the patients with the "cardinal" indications. Similar criteria were followed by Desmond and Seargeant (1957) in selecting patients for emergency partial gastrectomy, and also by Jones (1960), whose follow-up study shows that of 20 partial gastrectomies for perforated chronic ulcers (16 D.U.) only one had a poor result which required subsequent total gastrectomy. Reference to our simple-suture series confirms that these indications are appropriate. On such a system of selection, 32 out of 54 established ulcers might have been prevented from causing further major symptoms; while of 22 acute ulcers, which would still have been sutured, only three have had further trouble. Thus 51 of 76 patients $(67 \%)$ would have received the " right" treatment. This seems to us a very satisfactory proportion when compared with the grounds for such prophylactic operations as cholecystectomy for uncomplicated gallstones, or herniorrhaphy done to eliminate the risk of strangulation. Such a procedure, however, is justified only if it is itself devoid of any hazard comparable to that which it is designed to forestall. Partial gastrectomy as an emergency procedure must be expected to carry at least as high an early mortality rate as when performed electively. Welbourne and Johnston (1961) suggest an overall figure of $4 \%$ for the latter. The literature on the late complications of Polya gastrectomy has become voluminous (Muir, 1949 ; Wells, 1954 ; Stammers, 1955), hence the swing toward vagotomy and a drainage procedure as the primary elective surgical treatment for some or all duodenal ulcers (Dragstedt, 1959 ; Beattie, 1950 ; Burge and Clarke, 1959). For use in the treatment of perforated duodenal ulcer, vagotomy and a drainage procedure presents advantages over partial gastrectomy, in that it can be performed with greater dispatch and with much less extensive dissection-factors of importance in the presence of peritoneal soiling. In addition, pyloroplasty (or anterior pylorectomy) permits examination of the duodenum from within to assess the degree of pyloric stenosis, and to establish whether there is also a posterior ulcer. A possibly difficult duodenal stump closure is replaced by pyloroplasty, which has not proved technically difficult ; the middle part of a Mikulicz pyloroplasty, which is under most tension, employs normal tissues remote from the ulcer. Furthermore, these procedures are much more easily performed immediately than at a second operation, when adhesions are often a great nuisance.

In this series of 61 patients, vagotomy and a drainage procedure done for perforated duodenal ulcer has been shown to have a mortality of $5 \%$, two out of three of whom were very poor risk patients. This is compared with the published mortality for simple suture of Gilmour (1953) $4.4 \%$, Heslop et al. (1952) $4.7 \%$, and Avery Jones and Doll (1953) $3.3 \%$, though admittedly the least fit subjects were rejected from our series. Pierandozzi et al. (1960) among 75 cases of perforated duodenal ulcer treated by vagotomy and pyloroplasty had one death, due to electrolyte imbalance on the sixth day $(1.3 \%$ mortality). Their patients were selected for fitness, being aged 55 or less, with perforation for less than 12 hours and no persistent shock or excessive peritoneal soiling. Table IV shows the post-operative morbidity in the present series, which, including as it does all but the grossly unfit patients, must be judged low by any standards. Pierandozzi et al. (1960) experienced "serious" complications in two of their cases-one with a pelvic abscess and one with gastric retention which required gastrojejunostomy on the 26th day. In none of their cases did mediastinitis occur. Herrington (1961) also reported 30 perforations treated by vagotomy and antrectomy without mediastinitis being evident. Thus this selected group of patients with perforation of an established duodenal ulcer should have obtained the long-term benefits of vagotomy and drainage, with approximately the same mortality as, and no 
higher morbidity than, they would have had if they had been treated by simple suture.

It remains to examine the late results of this series to see to what extent the definitive operation did reduce the risk of further major symptoms, which would be predicted within two years in $59.6 \%$ of these patients if treated by simple suture. In fact, after vagotomy only $10.3 \%$ of cases had poor results, while a further $5 \%$ were untraceable. Included among the poor results are two patients with incomplete vagotomies, one of whom has now undergone transthoracic completion, while the other has become symptom-free. In round figures, it seems that the number of poor results has been cut from $60 \%$ to $10 \%$ in this group, so $50 \%$ have been saved from further serious ulcer disability within the relatively short period of this follow-up.

\section{Conclusion}

We consider that the present treatment of choice for patients with perforated duodenal ulcers, known by their history or shown by the operative findings to be chronic, is emergency vagotomy and pyloroplasty. Patients lacking such evidence of chronicity or concomitant bleeding should be treated by simple suture of the perforation, as should those judged unfit for the more major procedure on account of their very poor general condition.

\section{Summary}

A series of 61 patients with perforated duodenal ulcers treated by vagotomy and a drainage procedure is presented.

The prognosis following simple suture of perforated duodenal ulcer is discussed, and indications to be employed in selection for primary definitive procedures are assessed. Historical or operative evidence of chronicity carries a $60 \%$ risk of further ulcer symptoms, whereas acute ulcers usually follow a benign course after perforation.

The choice of definitive procedure to be employed as an emergency rests between partial gastrectomy and a vagotomy- and-drainage procedure. Reasons are given for preferring the latter.

In this series vagotomy and a drainage procedure were carried out with no higher mortality or morbidity than would be expected for simple suture. The late results were satisfactory in that only $10 \%$ experienced serious symptoms, as compared with $60 \%$ of such patients after simple suture.

Vagotomy and a drainage procedure is recommended as the treatment for those perforated duodenal ulcers with historical or operative evidence of chronicity.

We should like to thank the surgeons of the Leicester Royal Infirmary for permission to study their patients, and in particular Mr. D. C. McGavin for much helpful criticism.

\section{REFERENCBS}

Avery Jones, F., and Doll, R. (1953). Brit. med. F., 1, 122.

Beattie, A. D. (1950). Lancet, 1,525.

Burge, H., and Clark, P. A. (1959). Brit. med. F., 1, 1142.

Desmond, A. M., and Seargeant, P. W. (1957). Brit. F. Surg., 45, 283.

Dragstedt, L. R. (1959). Proc. roy. Soc. Med., 52, 835.

Gilmour, J. (1953). Lancet, 1, 870.

Graham, R. R. (1937). Surg. Gynec. Obstet., 64, 235.

Harbrecht, P. J., and Hamilton, J. E. (1960). Ann. Surg., 152, 1044

Herrington, J. L. (1961). Surgery, 49, 827.

Heslop, T. S., Bullough, A. S., and Brun, C. (1952). Brit. F. Surg., 40, 52 .

Illingworth, C. F. W., Scott, L. D. W., and Jamieson, R. A. (1946). Brit. med. F., 1, 787.

Jones, P. F. (1960). Postgrad. med. 7., 36, 768.

Judin, S. S. (1937). Surg. Gynec. Obstet., 64, 63.

Lewis, B., and Hamilton, J. E. (1956). Amer. Surg., 22, 204.

Lowdon, A. G. R. (1952). Lancet, 1, 1270.

Muir, A. (1949). Brit. F. Surg., 37, 165

Nuboer, J. F. (1951). Lancet, 2, 952.

Pierandozzi, J. S., Hinshaw, D. B., and Rogers, F. (1957). West. F. Surg., 65, 139.

_- and Stafford, C. E. (1960). Amer. 7. Surg., 100, 245.

Stammers, F. A. R. (1955). Ann. roy. Coll. Surg. Engl., 17, 373.

Taylor, H. (1957). Gastroenterology, 33, 353.

Welbourn, R. B., and Johnston, D. A. (1961). In British Surgical Practice, Surgical Progress, edited by E. R. Carlin and J. P. Ross, p. 301. Butterworths, London.

Wells, C. (1955). Ann. roy. Coll. Surg. Engl., 16, 145.

\title{
Results of Vagotomy with the Electrical Stimulation Test : An Interim Report
}

\author{
HAROLD W. BURGE,* M.B.E., M.B., F.R.C.s. ; ALAN MORTON GILL, $\dagger$ M.D., F.R.C.P. \\ RONALD H. LEWIS, $\ddagger$ M.B., B.CH., B.SC., F.R.C.S.
}

Brit. med. F., 1964, 2, 17-21

A report of the results of vagotomy with simple drainage for duodenal ulcer can be read only in the light of an understanding of the causes of recurrent ulceration.

If we exclude the Zollinger-Ellison syndrome, then there are two causes usually recognized.

1. Incomplete Nerve Section.-This is well established as the most important cause of recurrent ulceration. Dragstedt (1948) has shown in the laboratory that small retained nerve trunks may give rise to considerable acid secretion, and it has been demonstrated, by using the electrical stimulation test (Burge, unpublished work), ${ }^{1}$ that small retained trunks may cause recurrent ulceration in man. The incomplete-nerve-section

* Surgeon, West London Hospital, London.

+ Physician, West London Hospital, London.

t Pesident Assistant Surgeon, West London Hospital, London.

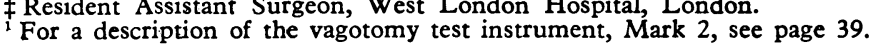

rate when the electrical stimulation test is not used is generally considered to be about $30 \%$.

2. Antral Retention.-The evidence that antral retention is a cause of recurrent ulceration is strong, and this cause is widely accepted in the world of gastric surgery. Such ulcers are generally thought to be due to an augmented hormonal phase of acid secretion from an antrum deranged by retention and by $p \mathrm{H}$ change.

As the results given in the present paper depend in part on this important cause of recurrent ulceration, some of the evidence in support of it is summarized below.

1. Antral retention causes secretion of acid in a denervated (Heidenhain) pouch in dogs. So do $\mathrm{pH}$ changes.

2. When vagotomy was done without either pyloroplasty or gastrojejunostomy, gastric retention was common, and lesser-curve 